\title{
Orthodontic Management of Skeletal Class-II Malocclusion with Horizontally Impacted Maxillary Canine: A Case Report
}

\author{
Sanjay Prasad Gupta, Shristi Rauniyar
}

\section{Author Info:}

${ }^{1}$ Department of orthodontics and Dentofacial Orthopedics, Tribhuvan University Dental Teaching Hospital, Institute of Medicine, Tribhuvan University, Kathmandu, Nepal ${ }^{2}$ Dental Villa- Orthodontic center \& speciality dental clinic, Kathmandu

*Corresponding Author:

Dr. Sanjay Prasad Gupta

Assistant Professor and

Consultant Orthodontist

Email/Contact: sanjayagupta2000@gmail.com +977-9843585923

ORCID iD: https://orcid. org/0000-0002-2510-5699

\section{ABSTRACT}

Management of skeletal class II relation in growing patient require careful evaluation of growth status, proper diagnosis and treatment plan to address the patient's need. Twin block is the appliance of choice among functional appliance to correct the skeletal class II malocclusion due to its acceptability by the patient and simplified design. Maxillary canine impaction is the second most prevalent impaction after the third molars. Treatment of maxillary canine impaction is usually a challenge to orthodontic approach as the defect lies in the esthetic region of the jaw.

This case report describes the orthodontic management of a 9 years male patient having skeletal Class II malocclusion with horizontally impacted maxillary canine. Some modifications in the treatment mechanics are deemed essential to address the patient's need for achieving the optimal esthetic and to improve the occlusion.

Twin block is beneficial for the treatment of skeletal malocclusion in a growing patient to achieve the maximum benefit. The orientation of impacted teeth may change from horizontal to favorable one, hence it should be considered a viable treatment alternative. In such case, early diagnosis and interception at the right time along with radiographic follow-ups are necessary to achieve successful results.

Keywords: Canine Impaction, Class II malocclusion, Growth modification, Twin block appliance

QR Code
Scan Me for
Received: 11 March 2020; Article Info




\section{INTRODUCTION}

Several treatment options are available for correction of skeletal class II relation depending on the growth and severity of the skeletal jaw base discrepancy. There are three alternatives for treating any skeletal problem- growth modification, dental camouflage and orthognathic surgery.

Myofunctional appliances are an appliance that utilizes the forces generated by the muscles to achieve dental and skeletal changes. Clark introduced the Twin Block appliance in 1988. ${ }^{1}$ It is the most commonly used functional appliance due to its acceptability by patients and simplified design. The Twin Block appliance along with good patient compliance gives fast and excellent results and this is why it has become a popular choice for treatment of skeletal class II malocclusion in growing patients. ${ }^{2}$

The teeth most frequently impacted in descending order are the mandibular and maxillary third molars, the maxillary canines, the mandibular and maxillary second premolars and the maxillary central incisors. ${ }^{3,4}$ Canine impaction is ten to twenty times more common in the maxilla than in the mandible. ${ }^{3}$

The lack of eruption may be associated with several factors, such as the presence of a supernumerary tooth, prolonged retention of the deciduous tooth, abnormal position of the impacted tooth, lack of space for eruption, root lacerations, alveolar or dental trauma and ankyloses. ${ }^{5-7}$ The reported frequency of palatal versus buccal impaction varies from rates of $2: 1$ to as high as $12: 1 .^{8}$

Maxillary canines are of great important for both aesthetic and functional aspects, since they provide support of the lip and facial muscles, play a vital role as tissue support at the corner of the mouth and their position is in the turning point of the dental arch. ${ }^{9}$

Failure of canine eruption due to impaction will affect the occlusion and may even influence the psychological development of the affected people. ${ }^{10}$

Treatment of maxillary canine anomaly is usually a challenge to orthodontic approach as the defect lies in the anterior region that affects the appearance much. ${ }^{11}$

The timing of orthodontic treatment, the type of surgical procedure to expose the impacted tooth, the necessary orthodontic mechanics, and potential problems with treatment vary depending on which tooth is impacted and its position in the jaw. ${ }^{12}$

This patient was treated in two phases; first, the functional phase using the twin Block appliance, followed by the second phase of fixed orthodontic appliance with impacted canine brought in to proper alignment that showed poor prognosis previously.

\section{CASE PRESENTATION}

\section{Diagnosis and Etiology:}

A 9years old male patient was referred for orthodontic consultation. His chief complaint was the presence of gap in the front region of upper jaw. He had no relevant family history, no significant prenatal, post-natal and medical history, and no history of parafunctional habits. He was very conscious of the appearance and the space present in the upper front teeth. On functional examination, there was no signs and symptoms of temporomandibular joint dysfunction.

On clinical examination, he had a convex profile with a symmetric face and lip incompetency at rest. Intraorally, there was a Class II molar and canine relationship bilaterally. The overbite was excessive and the over erupted mandibular incisors also impinged on the palatal gingiva, lingual to the maxillary incisors having overjet of $5 \mathrm{~mm}$ and overbite of $8 \mathrm{~mm}$. The both maxillary and mandibular arch were U-shaped and had mild spacing in upper arch and mild crowding with an excessive curve of Spee bilaterally in the lower arch.

The panoramic radiograph at the age of 9 years showed horizontally impacted upper right canine. The overall alveolar bone level was within normal limits. The cephalometeric analysis showed a skeletal Class II antero-posterior discrepancy with an ANB angle of $8^{\circ}$ (SNA: 84; SNB: $76^{\circ}$ ) and a horizontal growth pattern, as shown by an FMA of $21^{\circ}$ and SNGoGN of $29^{\circ}$.

\section{Growth evaluation:}

According to Demirjian dental formation stages ${ }^{13}$, patient was in stage D that is crown formation of left mandibular second molar is complete, extending down to the cemento-enamel junction and beginning of root formation was seen in the form of a spicule.

According to Baccetti et $\mathrm{al}^{14}$ stages of cervical vertebral maturation, patient was in cervical stage 2 (CS2) that is concavity was present at the lower border of C2. The bodies of both C3 and C4 were still trapezoid in shape. According to them, the peak in mandibular growth will occur on an average of 1 year after this stage. So, we have waited for one and half year to attain the optimal time for starting the treatment of mandibular deficiencies by means of functional jaw orthopedics (Fig. 1). 


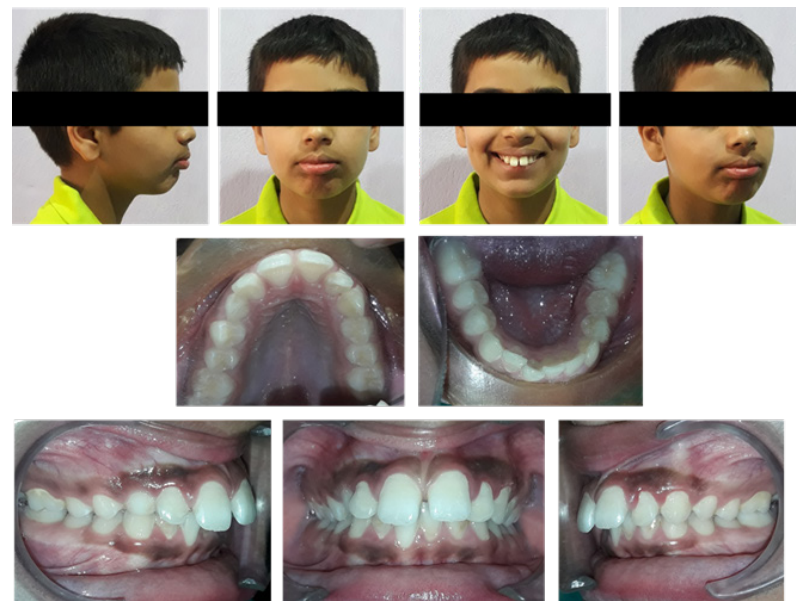

Figure 1: Pretreatment photographs before twin block treatment

Treatment Objectives: The treatment objectives were to correct upper spacing and deep overbite, establish class I molar and canine relation, achieve optimal occlusion, maintain facial balance and improve the esthetics.

Treatment Plan: The patient had a skeletal class II pattern and horizontal growth pattern. As the patient was in active growth stage so growth modulation with twin block was planned. The positive visual treatment objective (VTO) was found while advancing the mandible manually at edge to edge.

Treatment progress: As a part of phase I treatment for growth modulation, removable twin block as a functional appliance was placed and monitoring was done every month and it was kept for 12 months. On
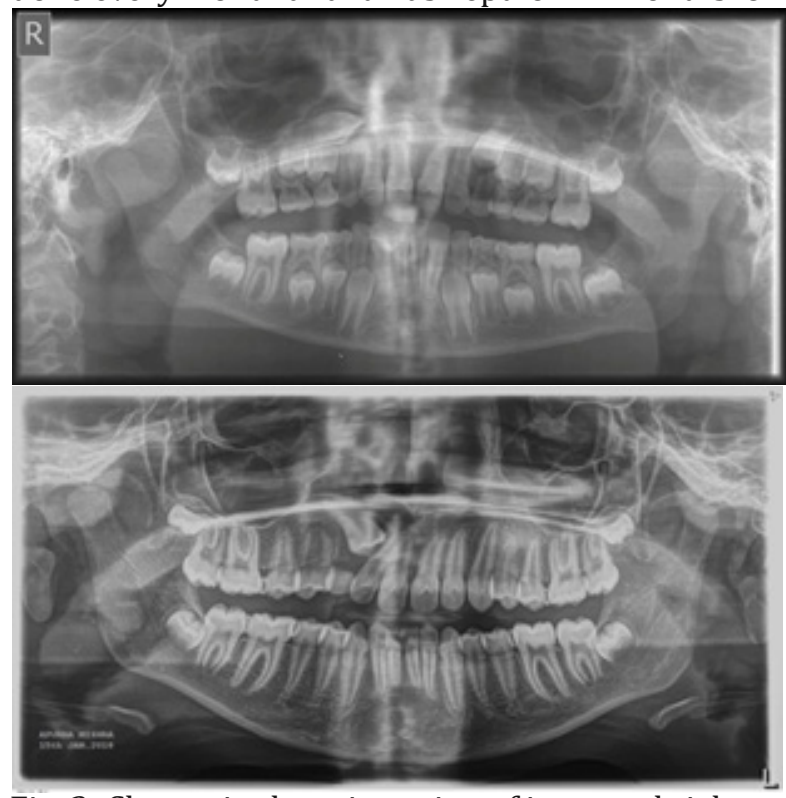

Fig. 2: Change in the orientation of impacted right upper canine after 2 years
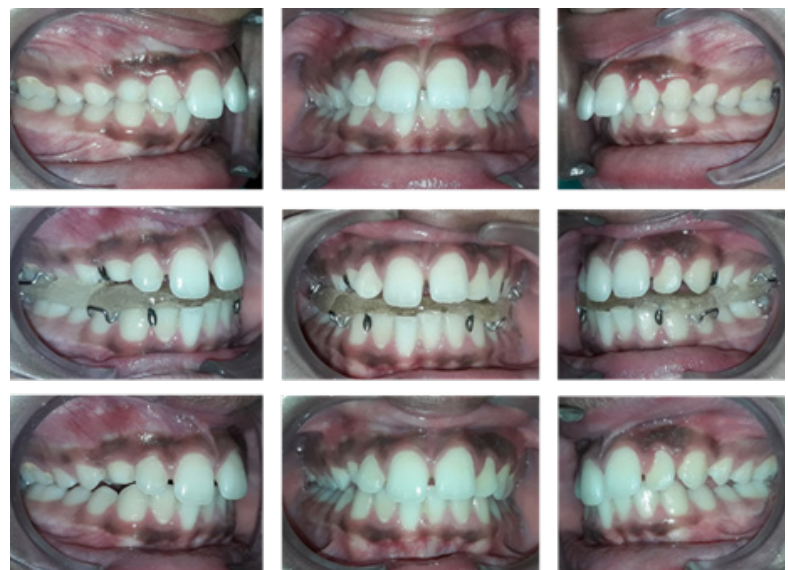

Fig. 3 Intraoral photographs during and after twin block treatment

orthopantamogram, after the twin block treatment, the orientation of impacted right upper canine changed from horizontal to slight vertical (Fig. 2).

After twin block treatment, the class II molar relationship changed to Class I molar relationship and facial profile was improved (Fig. 3). On cephalometric evaluation, the mandibular growth
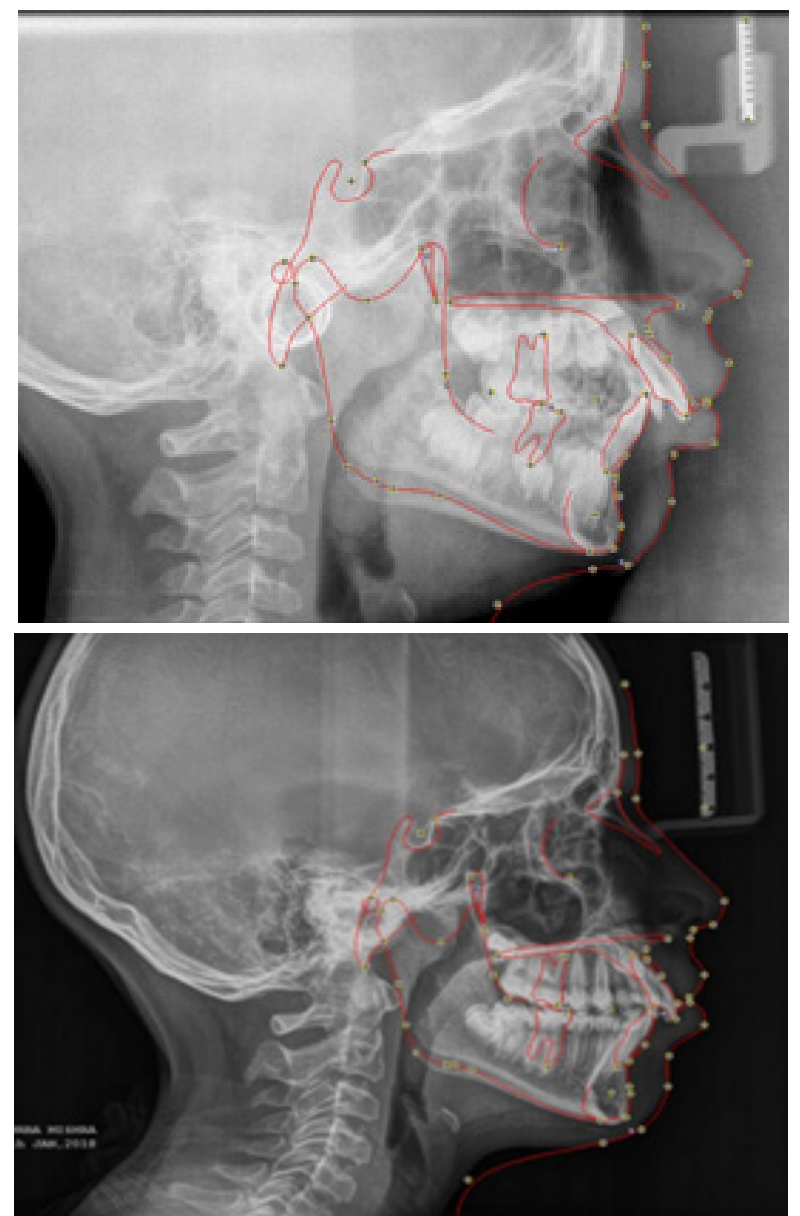

Fig. 4: Skeletal changes after twin block treatment 
Table 1: Comparative cephalometric parameters

\begin{tabular}{lcccc}
\hline $\begin{array}{l}\text { Cephalometric } \\
\text { parameters }\end{array}$ & $\begin{array}{l}\text { Clinical } \\
\text { norms }\end{array}$ & $\begin{array}{l}\text { Pre-treatment } \\
\text { values }\end{array}$ & $\begin{array}{l}\text { Mid treatment } \\
\text { (Values after twin block) }\end{array}$ & $\begin{array}{l}\text { Post-treatment } \\
\text { values }\end{array}$ \\
\hline SNA & $82 \pm 2^{\circ}$ & $84^{\circ}$ & $84^{\circ}$ & $85^{\circ}$ \\
SNB & $80 \pm 2^{\circ}$ & $76^{\circ}$ & $80^{\circ}$ & $81^{\circ}$ \\
ANB & $2 \pm 2^{\circ}$ & $8^{\circ}$ & $4^{\circ}$ & $4^{\circ}$ \\
Wits & $0-(-) 1 \mathrm{~mm}$ & $5 \mathrm{~mm}$ & $3 \mathrm{~mm}$ & $1 \mathrm{~mm}^{\circ}$ \\
FMA & $25 \pm 2^{\circ}$ & $21^{\circ}$ & $24^{\circ}$ & $27^{\circ}$ \\
SN-GoGn & $32 \pm 2^{\circ}$ & $29^{\circ}$ & $31^{\circ}$ & $34^{\circ}$ \\
Max.I-NA & $22 \pm 2^{\circ}$ & $26^{\circ}$ & $20^{\circ}$ & $22^{\circ}$ \\
Man.I-NB & $25 \pm 2^{\circ}$ & $27^{\circ}$ & $28^{\circ}$ & $28^{\circ}$ \\
LI-A-Pog & $2.7 \pm 1.7 \mathrm{~mm}$ & $2 \mathrm{~mm}$ & $4 \mathrm{~mm}$ & $4 \mathrm{~mm}^{\circ}$ \\
IMPA & $90 \pm 2^{\circ}$ & $94^{\circ}$ & $96^{\circ}$ & $95^{\circ}$ \\
Interincisal & $134^{\circ}$ & $118^{\circ}$ & $121^{\circ}$ & $124^{\circ}$ \\
angle & & & &
\end{tabular}

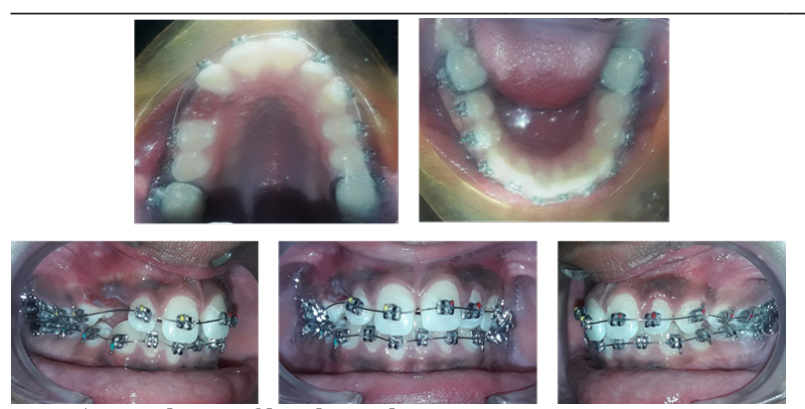

Fig. 5 Bonding of both arches
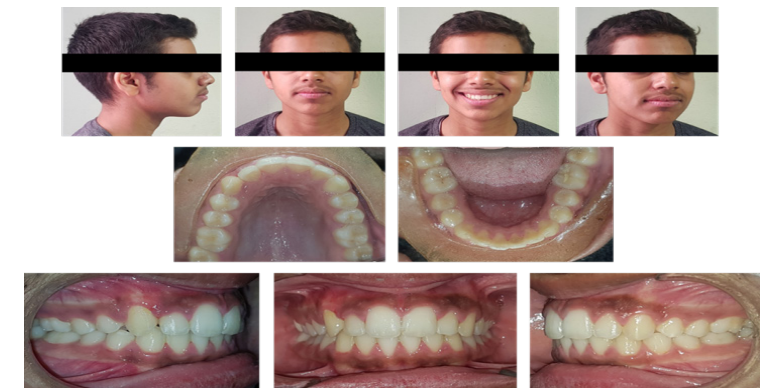

Figure 6: Post treatment extraoral and intraoral photographs

had increased (Fig. 4). This phase was followed by phase II that is treatment with fixed appliance. Upper right deciduous canine was extracted. Both arches were bonded with fully programmed preadjusted 0.022 MBT prescription brackets (Fig. 5). The arches were aligned using the following sequence of archwires; 0.012 NiTi, 0.014 NiTi and 0.016 NiTi.

Later, $0.018 \mathrm{ss}$ wire placed followed by maintaining the space for impacted canine with open coil spring. Surgical exposure of the impacted right canine was made from the buccal aspect and attachment was placed for traction of the canine. Canine was brought in to alignment using piggyback NiTi technique. Later
$0.019 \times 0.025$ stainless steel arch wire was placed to level and improve the torque of the upper incisors. Finishing and detailing was done and the appliance was debonded. The total duration was 26 months including 12 months of phase I and 14 months of phase II treatment.

\section{Treatment Results:}

The posttreatment facial photographs showed a remarkable improvement in patient's profile and facial esthetics (Figure 6). Intraorally, an optimal overbite and overjet relationship was established. A well-interdigitated buccal occlusion with class I molar relationship with class I canine relationship on both sides and coincided upper and lower dental midlines with the facial midline were achieved. There was canine guidance in lateral excursions with proper anterior guidance without balancing side interferences. The post-treatment cephalometric radiograph showed significant changes in the dental and skeletal measurements after treatment. The pretreatment, mid treatment and posttreatment cephalometric parameters are presented in Table 1. A post treatment panoramic radiograph revealed good root parallelism.

\section{DISCUSSION}

A Clinical examination revealed that the patient had Angle's Class II division 1 malocclusion on underlying skeletal Class II base relationship with orthognathic maxilla and retrognathic mandible having horizontal growth pattern. On growth evaluation, patient was in stage D Demirjian dental formation stage ${ }^{13}$ and Baccetti et al ${ }^{14}$ cervical stage 2 (CS2) stage of cervical vertebral maturation. According to them, the peak 
in mandibular growth will occur on an average of 1 year after this stage.

CS3 represented the ideal stage to begin functional jaw orthopedics, as the peak in mandibular growth would occur within the year after this observation. Study by Jamal et $\mathrm{al}^{15}$ also concluded that skeletal maturation can be reliably assessed with dental calcification stages of permanent mandibular second molar for Nepalese orthodontic patients and the timing of peak skeletal maturation coincides with dental calcification stages $F$ and $G$ for females and stage $\mathrm{G}$ for males.

Both these growth assessment method suggested to wait for the active growth phase, hence we have waited for one and half year to attain the optimal time to start the treatment of mandibular deficiencies by means of functional jaw orthopedics. The mode of action of myofunctional appliances may differ depending on the design; however, their effect is produced from the forces generated by altering the balance of the forces of the musculature. ${ }^{16,17}$ Twin Block functional appliance has several well established advantages including the fact that it is well accepted by the patients, robust, easily repairable and can be used in permanent as well as mixed dentition.

The primary objective of utilizing Twin Block therapy remains the same as that of other functional appliances, i.e., inducing the growth of condylar cartilage which leads to increase in the mandibular length and restriction of the maxillary growth. Maxillomandibular sagittal relationship has improved as angle ANB decreased from $8^{\circ}$ to $4^{\circ}$. After the treatment, mandibular plane angle has increased by $3^{\circ}$. These findings are in accordance with Pancherz. ${ }^{18}$

Surgical management of unerupted teeth depends upon a thorough understanding of anatomic, physiologic and pathologic factors. Attention has been given to problems of eruption in the maxillary anterior region.

The tooth germ of the maxillary canine originates high in the maxillary sinus just underneath the orbit at 4-5 months of pregnancy. Calcification begins 5-6 months after birth, and the maxillary canine teeth generally erupt in the oral cavity at around the age of ten. The eruption path for the maxillary canine is the longest among all teeth. The tooth germ of the maxillary canine is located in the most complicated area of the facial bones, and the time from the formation of the tooth germ until the eruption of the tooth is prolonged for these teeth. Therefore, various factors can cause positional abnormalities.
The etiology of maxillary canine tooth impaction remains obscure. Several theories have been proposed to explain the susceptibility of these teeth to impaction. ${ }^{11,19}$ Canine teeth that are subject to severe horizontal impaction in a labial position are less likely to erupt properly, even after the cause of impaction is eliminated. ${ }^{20}$

Surprisingly in this case, the orientation of impacted canine changed from horizontal to slight vertical with the span of 2 years. Later the canine was tracted to it's position followed by surgical exposure from the labial side without having any root resorption of it's adjacent teeth.

\section{CONCLUSION}

Functional appliance like twin block is beneficial for the treatment of skeletal malocclusion in a growing patient to achieve the maximum benefit. The orientation of impacted teeth may change from horizontal to favorable one, hence it should be considered a viable treatment alternative. In such case, early diagnosis and interception at the right time along with radiographic follow-ups are necessary to achieve successful results.

Acknowledgments: We would like to thank the patient and their parents for signing the letter of consent to publish his treatment records.

\section{REFERENCES}

1. Clark WJ. The twin block technique: A functional orthopedic appliance system. Am J Orthod Dentofacial Orthop. 1988;93:1-18. https:// doi.org/10.1016/0889-5406(88)90188-6 [PubMed] [Google Scholar]

2. Gandhi V, Mehta F, Joshi H. Treatment of class II malocclusion and impacted canines with twophase orthodontic treatment. Contemp Clin Dent. 2017;8:161-6. https://doi.org/10.4103/ ccd.ccd 394 16 [PubMed] [Google Scholar]

3. Kuftinec MM. and Shapira Y. The impacted maxillary canine: I. Review of concepts. J dent Child. 1995;62:317-24. [PubMed] [Google Scholar]

4. Kuftinec MM. and Shapira Y. The impacted maxillary canine: II. Clinical approaches and solutions. J dent Child. 1995;62:325-34. [PubMed] [Google Scholar]

5. Bishara SE. Impacted maxillary canines: a review. Am J Orthod Dentofacial Orthop. 1992;101(2):159-71. https://doi. org/10.1016/0889-5406(92)70008-X 
[PubMed] [Google Scholar]

6. Kurol J. Early treatment of tooth-eruption disturbances. Am J Orthod Dentofacial Orthop. 2002;121:588-91. https://doi.org/10.1067/ mod.2002.124173 [PubMed] [Google Scholar]

7. Andrade Jr. I, Paschoal MAB, Santos TO. Spontaneous eruption of severely impacted teeth: The report of two cases. J Clin Exp Dent. 2019;11(5):e491-5. https://doi.org/10.4317/ jced.55514 [PubMed] [Google Scholar]

8. Nanda R. Biomechanics in Clinical Orthodontics. W.B. Saunders Co., Philadelphia. 1997;99-108. [FullText] [PubMed] [Google Scholar]

9. Premkumar S, Shameer SF, Tovani-Palone MR. Management of impacted maxillary canines: a case report Electron J Gen Med 2019;16(5):em155. https://doi.org/10.29333/ ejgm/108498 [PubMed] [Google Scholar]

10. Seehra J, Yaqoob O, Patel $S$ et al. National clinical guidelines for the management of unerupted maxillary incisors in children. $\mathrm{Br}$ Dent J. 2018;224(10):779-85. https://doi. org/10.1038/sj.bdj.2018.361 [PubMed] [Google Scholar]

11. Kettle MA. Treatment of the unerupted maxillary canine. Dent Pract Dent Rec 1958;8:245-55. [PubMed] [Google Scholar]

12. Kokich VG, Mathews DA. Impacted teeth: surgical and orthodontic considerations. In: McNamara Jr JA, editor. Orthodontics and dentofacial orthopedics. Ann Arbor, Mich: Needham Press; 2001. [PubMed] [Google Scholar]

13. Baccetti T, Franchi L, James A, McNamara J. The cervical vertebral maturation (CVM) method for the assessment of optimal treatment timing in dentofacial orthopedics. Semin Orthod. 2005;11:119-29. https://doi.org/10.1053/j. sodo.2005.04.005 [PubMed] [Google Scholar]

14. Demirjian A, Goldstein H, Tanner JM. A new system of dental age assessment. Hum Biol. 1973;45(2):211-27. [PubMed] [Google Scholar]

15. Giri J, Shrestha BK, Yadav R, Ghimire TR. Assessment of skeletal maturation with permanent mandibular second molar calcification stages among a group of Nepalese orthodontic patients. Clin Cosmet Investig Dent. 2016;8:57-62. https://doi.org/10.2147/CCIDE. S93561 [PubMed] [Google Scholar]

16. Mills CM, McCulloch KJ. Treatment effects of the twin block appliance: A cephalometric study. Am J Orthod Dentofacial Orthop 1998;114:15-24. $\quad$ https://doi.org/10.1016/ s0889-5406(98)70232-x [PubMed] [Google Scholar]

17. Mills JR. The effect of functional appliances on the skeletal pattern. Br J Orthod 1991;18:267-75. https://doi.org/10.1179/bjo.18.4.267 [PubMed] [Google Scholar]

18. Pancherz H. The mechanism of class II correction in Herbst appliance treatment. Am J Orthod Dentofacial Orthop 1982;82:104-13. https:// doi.org/10.1016/0002-9416(82)90489-4 [PubMed] [Google Scholar]

19. Becker A. The orthodontic treatment of impacted teeth. 1998: 25-150, Martin Dunitz Ltd., London. [FullText] [PubMed] [Google Scholar]

20. Mochizuki K, Tsujino K, Yonezu T, Yakushiji M. The horizontally impacted maxillary canine situated in a labial position. Tokyo dent. Coll. 1999;40(4):203-8. https://doi.org/10.2209/ tdcpublication.40.203 [PubMed] [Google Scholar] 